\title{
Oromandibular Limb Hypogenesis Syndrome Type I B as a Rare Clinical Variant: A Case Report and Review of the Literature
}

\author{
Azam Hosseini ${ }^{1}$ and Shabnam Sohanian (iD ${ }^{2, *}$ \\ ${ }^{1}$ Oral Medicine Department, Dental School, Semnan University of Medical Sciences, Semnan, Iran \\ ${ }^{2}$ Oral and Maxillofacial Pathology Department, Dental School, Semnan University of Medical Sciences, Semnan, Iran \\ "Corresponding author: Assistant Professor, Oral and Maxillofacial Pathology Department, Dental School, Semnan University of Medical Sciences, Semnan, Iran. Email: \\ shabnam.sohanian@gmail.com
}

Received 2019 August 16; Revised 2019 September 26; Accepted 2019 November 14.

\begin{abstract}
Introduction: Hypoglossia-hypodactyly is an uncommon genetic abnormality affecting the tongue and limbs. First, it was classified under a multipart group of disorders called oromandibular limb hypogenesis syndromes. The most extensively accepted etiology is intrauterine trauma. Hypoglossia, micrognathia of the mandible, and limb anomalies are the characteristic features of the syndrome.

Case Presentation: A 19-year-old female patient was admitted to the Oral Medicine Department of the Dental School, Semnan University of Medical Sciences, for a dental checkup. After obtaining informed consent, the necessary dental prophylaxis was performed. This case was unique because the patient had only aglossia and deformity in her right hand and fingers.

Conclusions: Since the disease is rare and presents as the first case in Iran, dentists must have knowledge about its clinical features and proper patient management. They also should explain the significance of systematic dental checkups, perfect oral hygiene, and the use of regular fluoride to patients. Therefore, the awareness of dentists is essential about diagnosis and appropriate referral to specialists.
\end{abstract}

Keywords: Oromandibular Limb Hypogenesis Complex, Oromandibular Limb Hypoplasia, Aglossia-Adactylia

\section{Introduction}

Oromandibular limb hypogenesis syndrome (OLHS) is a very rare disease characterized by a variety of disorders affecting the tongue and limbs (1). Although its etiology is still unknown, both genetic and environmental factors have been suggested as etiological factors. However, the most commonly accepted etiology is exposure to environmental factors during pregnancy such as maternal hyperthermia, radiation, medicines, and nutritional deficiencies (2). Some drugs such as diazepam and chlorpromazine are involved in the causation of OLHS, but their effects have not yet been proven (3-5). Individuals who suffer from this syndrome frequently display overlapping clinical manifestations such as aglossia, hypoglossia, adactyly, and hypodactyly (2). Three features that are necessary for the diagnosis of the syndrome include (1) variable size of the tongue (microglossia), (2) micrognathia of the jaw in the midline segment, and (3) varying severity of limb anomalies (3).

Aglossia is a particularly rare genetic disorder accompanying with inherited malformations such as micro- cephaly, adactylia, mental retardation, hypodactylia, deafness, palatal cleft, hypodontia, and anodontia (3). Rosenthal (6) first reported the occurrence of aglossia and adactylia.

Limb anomalies have a particularly variable range from syndactyly, referring to the partial separation of fingers, to amelia, referring to the missing of the limb (3). Generally, they tend to be distal to humerus and femur (1). Different variations may be seen in one or more limbs in the same patient or in different individuals $(1,3)$. There are some visceral anomalies associated with this syndrome including the imperforate anus, ileal atresias, absence of a kidney, and fused labia majora (3).

The best classification to describe hypoglossia and limb deformity in OLHS was declared by Hall (7). Nevertheless, Hall's classification cannot categorize aglossia and other associated abnormalities.

Here we present a patient with oromandibular malformations associated with a defect in her right hand and aglossia (aglossia-adactylia). 


\section{Case Presentation}

A 19-year-old female patient was admitted to the Oral Medicine Department of the Dental School, Semnan University of Medical Sciences, for a dental checkup. The patient had microstomia, misaligned teeth, and problems in speech but had no difficulty in swallowing and breathing. The patient was the third child of her parents who had four children. There was no history of similar results in the family and the parents had no history of consanguineous marriage.

On the general examination, she had no unusual finding except for deformity in her right upper limb with five nubbins attached to its distal part (Figure 1). The intraoral examination revealed microstomia, incompetent lips, constricted maxillary and mandibular arches, crowding in upper and lower anterior teeth, aglossia, and hypodontia. After a thorough evaluation of the patient, we arrived at a final diagnosis of oromandibular-limb hypogenesis syndrome type IB.

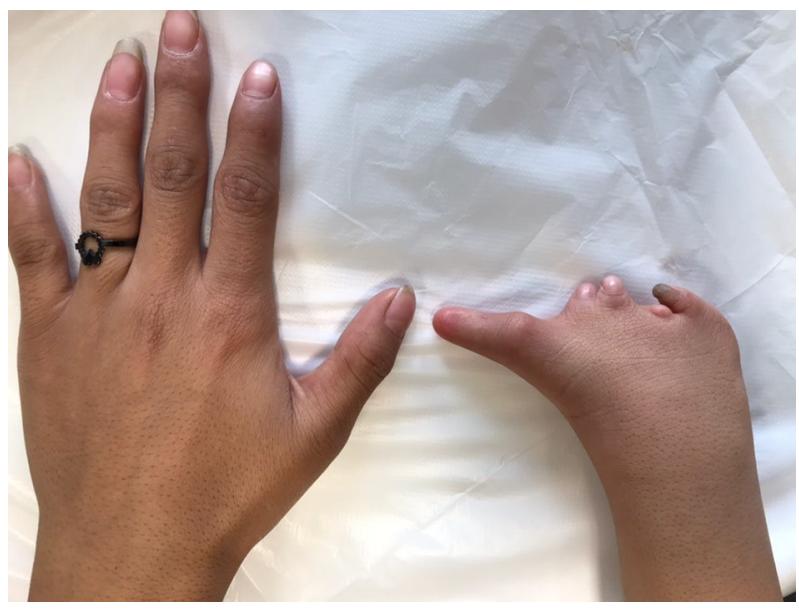

Figure 1. Deformity in the right upper limb with five nubbins attached to its distal part

Oral prophylaxis was performed after obtaining informed consent. The significance of systematic dental checkup, perfect oral hygiene, and the regular use of fluoride was explained to the patient.

\section{Discussion}

Oromandibular-limb hypogenesis syndrome is characterized by a variety of complaints affecting the tongue and limbs. These patients frequently have overlapping clinical features. Therefore, this complex syndrome has been classified to clarify the diagnosis (2). Hall's classification (7) is the best one to describe limb anomalies as presented in our patient. Consequently, our case was diagnosed with OLHS type 1-B2: Aglossia with adactylia.

Hall classified OLHS into five groups only with the essential principles of hypoglossia and limb defect. However, some authors reported cases that showed aglossia related to limbs and other congenital malformations (1). Preis et al. (8) remarked aglossia accompanying hypodactylia, anodontia, ventricular septal defect, epidermoid of the right eye, and paresthesia of the sixth and seventh cranial nerves. Recently, Kantaputra and Tanpaiboon (9) revealed the relationship between aglossia and microstomia, partial anodontia, mental retardation, microcephaly, and hypothyroidism. Higashi and Edo (10) reported the association of aglossia with conduction deafness. Here we present a case that showed an association between aglossia and hypodactylia. This case is the first reported OLHS case in Iranian literature. Therefore, it is necessary to supplementarily categorize Hall's classification established on aglossia and hypoglossia. Kalaskar et al. (2) recommended modifications for Hall's classification type IB (Table 1).

Both genetic and environmental factors have been mentioned as the OLHS etiology (4). A few reported cases had intrafamilial histories, but most reported cases were sporadic $(3,4)$. There has been no genetic mutation or chromosomal abnormalities for this syndrome to date $(3,4)$. However, the suggested etiologies include maternal hyperthermia, heredity, and positive drug history during pregnancy (14). Several authors have recommended that the use of numerous drugs such as meclizine, marijuana, and benzamide hydrochloride during pregnancy is the reason for this syndrome, but none has been proven (15).

During embryonic development, the anterior tongue is formed from the first branchial arch and the posterior part is created from the second and the third branchial arches. Therefore, hypoglossia is attributed to the failed growth of these three branchial arches (15-17).

Sucking, swallowing, taste, speech, perception, mastication, development of jaws and occlusion are the important functions of the tongue. Though the tongue is deficient or absent, activities such as swallowing and speech improve with time in the majority of the cases. This is conceivable by adaptive mechanisms of the orofacial assembly, which helps in swallowing, taste sensation, and feeding and improves speech $(12,14)$.

For maintenance of such patients, appropriate preventive procedures are essential including oral prophylaxis, fluoride therapy, and pit and fissure sealants. However, the complete rehabilitation of individuals with aglossia is complicated and necessitates a multidisciplinary approach. Surgical and orthodontic treatment would be required to correct jaw anomalies and malocclusion (15). 


\begin{tabular}{lcll}
\hline Table 1. Modification of Type I B Hall's Classification & & References \\
\hline Hall's Classification & Modified Subtypes & Clinical Features & Salles et al. (11), Gupta (12) \\
\hline Type I B (Aglossia) & Type I-B1 & Isolated aglossia & Nevin et al. (1), Purohit et al. (13) \\
& Type I-B2 & Aglossia with adactylia & Preis et al. (8), Kantaputra and Tanpaiboon (9) \\
& Type I-B3 & $\begin{array}{l}\text { Aglossia with hypodactylia (mental retardation, } \\
\text { cardiac defect, anodontia, hypothyroidism) }\end{array}$ & Higashi and Edo (10), Kalaskar et al. (2) \\
\hline
\end{tabular}

Consequently, timely diagnosis, constant maintenance, and a multidisciplinary approach are mentioned for the supervision of such patients.

\subsection{Conclusions}

Since this disease is rare and presents as the first case in Iran, dentists must have knowledge about its clinical features and proper patient management. They also should explain the significance of systematic dental checkup, perfect oral hygiene, and the use of regular fluoride to the patient. Therefore, the awareness of dentists about diagnosis and appropriate referral to specialists is essential.

\section{Footnotes}

Authors' Contribution: Study concept and design: Azam Hosseini; acquisition of data: Azam Hosseini; analysis and interpretation of data: Azam Hosseini and Shabnam Sohanian; drafting of the manuscript: Shabnam Sohanian; critical revision of the manuscript for important intellectual content: Shabnam Sohanian; statistical analysis: Azam Hosseini and Shabnam Sohanian; administrative, technical, and material support: Azam Hosseini; study supervision: Shabnam Sohanian

Conflict of Interests: There is no conflict of interest in this study.

Funding/Support: No funding/support is reported.

Informed Consent: Informed consent was obtained from the patient.

\section{References}

1. Nevin NC, Burrows D, Allen G, Kernohan DC. Aglossia-adactylia syndrome.J Med Genet. 1975;12(1):89-93. doi: 10.1136/jmg.12.1.89. [PubMed: 1121025]. [PubMed Central: PMC1013236].

2. Kalaskar RR, Godhane A, Kalaskar A, Demble S. A rare clinical variant of oromandibular limb hypogenesis syndrome type I B. Int J Clin Pediatr Dent. 2016;9(1):78-81. doi: 10.5005/jp-journals-10005-1338. [PubMed: 27274161]. [PubMed Central: PMC4890068].

3. Lustmann J, Lurie R, Struthers P, Garwood A. The hypoglossiahypodactylia syndrome. Report of 2 cases. Oral Surg Oral Med Oral Pathol. 1981;51(4):403-8. doi: 10.1016/0030-4220(81)90150-x. [PubMed: 6940078].
4. Meundi MA, Nair GR, Sreenivasan P, Raj AC. Oromandibular limb hypogenesis syndrome type IIB: Case report of hypoglossia-hypodactyly. Case Rep Dent. 2013;2013:370695. doi: 10.1155/2013/370695. [PubMed: 23431477]. [PubMed Central: PMC3575672].

5. Firth HV, Boyd PA, Chamberlain PF, MacKenzie IZ, Morriss-Kay GM, Huson SM. Analysis of limb reduction defects in babies exposed to chorionic villus sampling. Lancet. 1994;343(8905):1069-71. doi: 10.1016/s0140-6736(94)90182-1. [PubMed: 7909100].

6. Rosenthal R. Aglossia congenita: Report of a case of the condition combined with other congenital malformations. Am J Dis Children. 1932;44(2):383. doi: 10.1001/archpedi.1932.01950090121013.

7. Hall BD. Aglossia-adactylia. Birth Defects Orig Artic Ser. 1971;7(7):233-6. [PubMed: 5173209].

8. Preis S, Majewski F, Hantschmann R, Schumacher H, Lenard HG. Goldenhar, Mobius and hypoglossia-hypodactyly anomalies in a patient: Syndrome or association? Eur J Pediatr. 1996;155(5):385-9. doi: 10.1007/bfo1955267. [PubMed: 8741036].

9. Kantaputra P, Tanpaiboon P. Thyroid dysfunction in a patient with aglossia. Am J Med Genet A. 2003;122A(3):274-7. doi: 10.1002/ajmg.a.20269. [PubMed: 12966532].

10. Higashi K, Edo M. Conductive deafness in aglossia. $J$ Laryngol Otol. 1996;110(11):1057-9. doi: 10.1017/s0022215100135741. [PubMed: 8944882].

11. Salles F, Anchieta M, Costa Bezerra P, Torres ML, Queiroz E, Faber J. Complete and isolated congenital aglossia: Case report and treatment of sequelae using rapid prototyping models. Oral Surg Oral Med Oral Pathol Oral Radiol Endod. 2008;105(3):e41-7. doi: 10.1016/j.tripleo.2007.09.028. [PubMed: 18280945].

12. Gupta SR. Isolated aglossia congenita: A rare case of oromandibular limb hypogenesis syndrome type I B. J Oral Maxillofac Pathol. 2012;16(3):414-9. doi: 10.4103/0973-029X.102504. [PubMed: 23248477]. [PubMed Central: PMC3519220].

13. Purohit SK, Kumta SM, Rao PP, Thatte RL. An interesting case of aglossia-adactyly syndrome. Br J Plast Surg. 1989;42(2):228-9. doi: 10.1016/0007-1226(89)90209-9. [PubMed: 2702373].

14. Graham JJ, Edwards MJ, Edwards MJ. Teratogen update: gestational effects of maternal hyperthermia due to febrile illnesses and resultant patterns of defects in humans. Teratology. 1998;58(5):209-21. doi: 10.1002/(SICI)1096-9926(199811)58:5<209::AID-TERA8>3.0.CO;2-Q. [PubMed: 9839360].

15. Weingarten RT, Walner DL, Holinger LD. Tongue hypoplasia in a newborn. Int J Pediatric Otorhinolaryngol. 1993;25(1-3):235-41. doi: 10.1016/0165-5876(93)90058-b.

16. Bokesoy I, Aksuyek C, Deniz E. Oromandibular limb hypogenesis/Hanhart's syndrome: Possible drug influence on the malformation. Clin Genet. 1983;24(1):47-9. doi: 10.1111/j.13990004.1983.tb00068.x. [PubMed: 6616945].

17. Sharma G, Vengal M, Pai KM, Nagpal A. Hypoglossia Type 1A: Report of a case and review of literature with focus on clinical investigations. Indian J Dent Res. 2012;23(2):264-70. doi: 10.4103/0970-9290.100438. [PubMed: 22945721]. 